\title{
Study of Business English Teaching under MOOCs Age Buzhen Li ${ }^{1}$, Qiudi Zhu ${ }^{1}$ \\ ${ }^{1}$ Jiangxi College of Foreign Studies, Nanchang, Jiangxi, 330099 59624917@163.com
}

\author{
Keywords: MOOC; English Teaching; Oral English
}

\begin{abstract}
MOOC rely on teachers, schools, convenience of the Internet with its lightning speed, sweeping the globe, making the alliance the world-renowned universities have joined MOOC platform, dedication to the university's high-quality educational resources, and successfully make tens of million tastes the essence of world-renowned universities. MOOC rise, some people think it will replace the traditional higher education, in order to solve development difficulties, lower quality, high cost and other difficulties of the current higher education arise. MOOC also suggested that short-lived, can not replace the traditional higher education. Either way, the discussion about the current MOOC's already become a hot topic in the field of education. MOOC for more in-depth study, to let more people know and understand the rational MOOC, is of great practical significance. This paper uses literature and comparative law, MOOC education by analyzing the phenomenon from the perspective of education reveals MOOC concepts, features and functions. And through knowledge forms, teacher-student relationship, change the angle of the quality of education and contrast similarities and differences between traditional education MOOC between both predict the future trend of development, the new institutions of higher learning mode may appear at the future, so as to arrive In MOOC background, China's colleges and universities should make what the appropriate preparations.
\end{abstract}

\section{Introduction}

MOOC (Massive Open Online Course) development is the best example. MOOC is a free form of education for the public, "large-scale" means there will be different races from different countries and regions of the world, unimaginable number of people of different colors together to learn the same course, speaking for teachers "spanned" scene will truly see the "open" refers to everyone and free of charge, it will not really have to teach classes. "Online" means, all this occurs in the smooth flow of the network environment. Three-time Pulitzer Prize-winning American economist Thomas • Friedman said, "when suddenly become possible urgent needs, a major breakthrough will come .MOOC emergence breakthrough opens the door to higher education in early .2012, Daphne Koller Stanford University professor of computer private educational institutions with colleague Andrew Ng founded Coursera began offering free public courses .Coursera network launched just four months after enrollment reached one million, in July 2012, Coursera announced that there were 12 integrated University joined the company project. This twelve universities mainly California Polytechnic University, Georgia Institute of Technology, John • Hopkins University, University of California, San Francisco, University of Virginia and University of Washington, and after less than a year time, colleges and universities to cooperate with Coursera has increased 33 As of May 2014, there are 99 universities from 22 countries and regions through cooperation with Coursera's start as early as late 2012, the United States and many other celebrities universities are competing respected MOOC, there is there to Stanford University, Harvard University, Massachusetts Institute of Technology, etc. while there Coursera, Udacity and edX other online education platform. These platforms have international online education Troika support, through These platforms, allowing ordinary school students can be learning to the world-famous institutions of higher education courses, in addition, for students and teachers, can take advantage of online education more in-depth discussion, this can effectively increase student learning Interest .2013 On May 21, Tsinghua University, Beijing University, Hong Kong University and Hong Kong University of Science and Technology were announced to join the MOOC, become a member of .2013 edX on 
July 8, Fudan University and Shanghai Jiaotong University also announced to join the MOOC family with Coursera agreement, we committed to providing Chinese or English curriculum.

\section{The Impact of MOOC on Business English Education}

MOOC bring change is the most straight-on teaching methods change, MOOC broke thousands of years of university education followed by teacher-led small-scale traditional lecture-style teaching. It is web-based, fully play its extensive coverage of the characteristics, teaching resources can be more people use, so that a wider field covering education, student-centered, to fully exploit their initiative in the learning process through participatory build interactive learning community, it is to the content of university teaching, four aspects of the way, evaluation, and teaching and research have brought a revolutionary impact.

First, MOOC use of the Internet as a carrier, the high-quality curriculum resources of the world's top universities at very low cost passed on to the original can not get these resources from around the world all learners terminal devices, so that they can easily get the best quality anytime, anywhere learning resources. Currently, Coursera a platform on the release of 534 programs from 107 world-renowned universities, attracting more than 5.3 million students enrolled, in terms of the number of courses or number of student point of view, are the traditional university education can not match. As another example, according to Google's statistics, in 2012, Yale University: "Death Philosophy" a course, average weekly clicks in mainland China more than 3,000 times, if not MOOC, all these Chinese students are unable to experience another Professor Kagan humor and profound explanations, in addition, has passed the Internet, MOOC also outside of the instructional videos, other high-quality online education resources integration in the curriculum, such as electronic textbooks, learning software, so that the process of learning content and school They have become richer and more vivid, according to "Chronicle of Higher Education," the survey, 97\% of teachers in the use of original video MOOC, $75 \%$ of the use of open educational resources, only 9 percent use must buy the book obtained 5\% must be used buy books available.

Secondly, MOOC change the traditional teaching model is also reflected in the initiative will be returned to the school students, allow students according to their knowledge and ability to grasp the level of their own school schedule change into a choice of schools, fully embodies the "self-learning" concept Many newly developed teaching platform MOOC are trying to push through technical means to promote a teaching philosophy of reform, professor of artificial intelligence course has 160,000 students Udacity Schlumberger is one of the founders, he that the ideal is to establish a Udacity Network teaching model center, which allows students to complete the study by solving the problem, rather than listening to the teacher taught how to solve the problem, at present, including Udacity, Coursera, edX and other platforms have introduced the teachers and students, peer interaction channels, and more accurate operation, testing and evaluation methods. Again, MOOC assessment of student learning outcomes in specific evaluation methods and course certificate chain and so made a change, with the conventional educational methods have great differences. On the way, the three major US platforms or software to evaluate the use of peer evaluation way for students to provide feedback for the first time, while OCW forum on the forum can enjoy the exchange between teachers and students to address learning and teaching appearing problem, common progress and development. edX platform, though started late, but it is the vanguard of technological innovation network course, is to make use of the alumni resources for teaching and assessment of thousands of students to provide effective academic assessment, MIT professor Caesar developed software, task assignments and tests Reply Alumni volunteers from around the world non-rationing, both alumni of the clever use of resources for teaching and assessing the quality, but also to promote the alumni and students to interact directly and broaden opportunities for the two sides meritocracy or careers. In the course certification, MOOC previous network curriculum large difference is that it can complete the course students officially certified or accredited colleges and universities to get credit, even to achieve mutual recognition between different platforms, which is conducive while safeguarding the quality of teaching and the economic interests of the platform, a lot of reasons for students not acceptable in terms of university education, 
has great appeal, in September 2012, Colorado State University, to do more "global network of alumni," announced accept complete computer on Udacity Introduction science class students to transfer credits. All 33 top North American universities Coursera cooperation can be paid for the completion of the school curriculum for students certified. MIT also launched the first school gate Online Certification Courses 2011-2012 school year in the spring.

Finally, all parties hope to use along with large data MOOC comes from teaching and research reform fundamentally break these studies are small, time-consuming and difficult to promote the issue in a relatively short period of time allows researchers to take advantage of global students Guomo large research data obtained directly applied MOOC, for example, by thousands of students and scholars are not simultaneously watch instructional videos long period analysis, summed up when the video is longer than 8-10 minutes, the student tendency Unable patience in watching the video, which will be a short video channels teach good teaching effect.

\section{The Opportunities of English Teaching under the Background of MOOC}

English teaching while facing many problems and challenges in the Mu class background, but how to adapt to the new media, the key to self-media age of English teaching model innovation is the concept. As the leader of the English classroom teaching teachers, faced with this new class $\mathrm{Mu}$ appear teaching platform is deliberately avoided, or active participation, the result will be different. take advantage of Mu lesson in vocational English teaching process advantages and features, it has a positive effect for the rich and teaching methods to enhance the quality of teaching The main features of teaching under the $\mathrm{Mu}$ class platform that micro-video mode based on information processing theory, ordinary learner attention span of about 10 minutes or so. Therefore, the micro video with knowledge as the center point of each limited knowledge be taught within a period of time. This fragmented, decentralized mode of teaching will help students to absorb knowledge and mastery than traditional systematic and theoretical way professors are more likely to be accepted and understood.

The second major feature of the Mu class platform is interactive discussion module, generally with a Q \& A space, situational teaching, performance evaluation and other sub-modules. Q space, allows teachers and students, between life and open for all kinds of problems, interactive, rolling exchanges, inspired in the discussion, find ways and means to solve the problem, a final settlement, to share feelings and experiences. situational teaching places video, audio, images, documents and other forms of simulation exercises for the knowledge point practice and application process. Grading is open, fair and diverse forms, such as peer review, self-assessment system, open the job and so on. And the discussion is not time and space constraints, learning and flexible communication. Vocational English experience such as the interaction time is limited, many teachers and class size and other bottlenecks, can take advantage of this online interactive platform is solved. English teachers have more time online and exchange student at any time, students can also group discussions on the platform, eliminate the boundaries of the classroom in. Basic English integrated curriculum \& teaching process, teachers for students' learning process, learning difficulties, learning ability can grasp, and combined with the specific circumstances change teaching content and course schedule, you can upload the relevant teaching aids materials, teaching effectiveness benefit.

Flipped classroom is the classroom instruction to give students more time to change in order to grant traditional classroom-based model, emphasizing learning-based, focusing on the experience and interactive learning. In Basic English integrated curriculum, for example, are expected to preview, and import section Mu lessons can be placed on a platform in advance, so that students know the topics and heavy and difficult learning unit, complete related tasks. classroom teaching practice, there is more time to be internalized knowledge Keqianyuxi to discuss means of communication, Ask a question in class, debate, while the teacher has become the course participants and organizers, the classroom to the students, inspire students and review ideas and content, truly teaching and learning in the classroom teaching process, to stimulate students 
criticism thinking and ability to ask questions, rather than the traditional classroom lectures and silent Students' passive situation.

\section{Conclusion}

Mu lesson era unstoppable advantage Mu lesson is obvious today applied undergraduate colleges more and more attention to English, to improve students' English level is the requirement of the times, we should seize this opportunity Mu class, conducted in English education reform, to improve students' English proficiency.

\section{References}

[1] Apostolos Koutropoulos, Rebecca J. Hogue. How to Succeed in A MOOC-Massive Online Open Course, October 8, 2012.

[2] Cathy Sandeen, Assessment Place in the New MOOC World, Research \& Practice In Assessment, Volume8, 2013.

[3] Downes S. Places to Go: Connectivism \& Connective Knowledge. Innovate Online, 2008, 5(1).

[4] Dorsa Sadigh, Sanjit A. Seshia, and Mona Gupta. Automating Exerc- Cise Generation: A Steptowards Meeting the Mooc Challenge Forembedded Systems. In Proc. Workshop on Embedded Systems Education (Wese), October 2012.

[5] Feinberg Z. How Moocs Can Strengthen Democracy. 2012. 